\title{
Numerical Study on the Effect of Jet on the Operation of Powder Fuel Scramjet
}

\author{
H. M. Ding ${ }^{\dagger 1}$, C. F. Zhuo ${ }^{1}$, W. J. Hu ${ }^{2}$, H. Y. Deng ${ }^{1}$ and X. Chen ${ }^{1}$ \\ ${ }^{1}$ School of Mechanical and Engineering, Nanjing University of Science and Technology, Nanjing 210094, \\ China \\ 2 Yibin North Chuan'an Chemical Industry Co., Ltd, Sichuan 644219, China.
}

†Corresponding Author Email: dhm123njust@163.com

(Received April 11, 2021; accepted August 6, 2021)

\begin{abstract}
Metal powder fuel has high energy and volume calorific values, and it is an excellent power fuel for hypersonic aircraft in the future. However, metal powder has poor flow characteristics and is difficult to be effectively mixed with air when supersonic air is injected. The mixing degree of fuel and air is an important factor to the efficiency of the engine. One way to solve this problem is to introduce a jet (the primary jet) upstream of the powder fuel inlet to improve the mixing degree of fuel and increase the residence time. In this study, a doublehole jet two-dimensional scramjet combustor structure was established, the effects of different initial jet conditions on the performance of scramjets was studied and analyzed. The results show that the introduction of the primary jet can effectively improve the mixing degree of the powdered fuel and air in the combustion chamber, prolong the residence time of the particles in the combustion chamber and improves the combustion efficiency of the metal powder. However, both the combustion efficiency of the metal powder fuel and engine thrust increase and then decrease when the mass flow rate of the primary jet increases.
\end{abstract}

Keywords: Scramjet; Numerical simulation; Powder fuel; Jet; Combustion efficiency.

\section{INTRODUCTION}

Scramjet is currently one of the best power device to achieve hypersonic flight in the atmosphere (Wen et al. 2019). Relevant studies have shown that with the increase of the flying Mach number, the temperature of the air entering the combustion chamber continues to rise after the intake port are compressed. The hydrocarbon fuel used in the conventional ramjet are easily dissociated in high temperature environments, this causes the specific impulse of the engine to drop. Relevant studies have shown that the metal powder fuel does not have the above problem at high temperatures. In addition, the powder fuel also has higher energy and volumetric calorific value, which makes the powder fuel scramjet have higher specific volume and density specific impulse (Goroshin et al. 2001; Hu et al. 2017). Therefore, the research on metal powder fuel is vital for the scramjet.

The experimental studies have shown that the powder fuel can be effectively transported to the combustion chamber for combustion. Under the action of the ignition torch, the powder fuel can achieve rapid ignition and start, and the powder fuel can keep burning by itself after the torch ignited
(Shen et al. 2007 and 2008). In the experiment, the performance of the cavity and bluff body flame stabilizer were also compared. The results show that due to the poor fluidity of the powder particles and the poor flame stability of the cavity, the flame stability of a bluff body stabilizer is better, but the deposition around the stabilizer reduces the engine efficiency (SHEN et al.2009).

Due to the poor fluidity of the metal powder, it is not conducive to be mixed with air. Therefore, the effective mixing of the fuel and air has an important role in achieving high combustion efficiency of scramjet. At present, researchers have conducted a lot of research on the mixing of hydrocarbon in supersonic flow, including the use of various geometric structures, such as, oblique jets, central support plates and cavity combination. (Huang et al. 2011; Fuller et al. 1998; Gruber et al. 2004). Compared with wall injection, these devices can effectively improve the fuel mixing efficiency, but their geometry structure hinders the air flow in the combustion chamber, resulting in greater total pressure loss and higher requirements for structural 
thermal protection (Aryadutt et al. 2019). In addition, related studies have shown that the wall structure of the isolation section has a great influence on the degree of the fuel mixing. (Li Y. et al. 2020; Barzegar et al. 2019; Li Z. et al. 2020). The influence of the sinusoidal wall on the fuel mixing jet was studied. When the frequency of the sinusoidal since wave is sufficient, the appearance of the corrugated wall increases the mixing degree. At present, the fuel injection methods of scramjet are mainly side injection, and a large number of experimental and numerical studies have been carried out (Chapuis et al. 2013; Smart et al. 2006; Zhao et al. 2016; You et al. 2013; Mahesh et al. 2013; Sun et al. 2018;Liang et al. 2018 and 2020) and found that the complex unstable shock wave structure, the shear layer and their interaction in the jet form a major pair of vortices, which have a significant impact on the fuel mixing in the downstream area. The results shown that by installing multiple side injectors on the combustion chamber, the jet diffusion, penetration, vortex effect and mixing efficiency of multiple injectors were improved compared with a single injector (Vatslya et al. 2020; Pudsey and Boyce 2010; Gerdroodbary et al. 2016; Huang et al. 2018; Barzegar et al. 2016, and Taherinezhad et al. 2019 ). The wall injection has the advantages of simple structure, low thermal protection requirements and small total pressure loss. It has become the main injection method of powder fuel scramjet (Anugrah et al. 2019).

In this study, a gas jet channel is set in front of powder fuel jet channel of the scramjet. The effects of primary jets on the flow field change, the degree of powder mixing in the combustion chamber and the engine performance were analyzed by comparing the working conditions of different primary jets to improve the combustion efficiency of powder fuel and the overall performance of the engine.

\section{CALCULATION MODEL and METHOD}

\subsection{Basic Assumptions}

To increase the calculation speed, the working process of the powder fuel scramjet was assumed as follows:

1. The gas in the combustion chamber was idea, which conforms to the gas equation of state.

2. The aluminum powder is spherical and has no oxide film on the surface. The burned oxide is in a gaseous state, regardless of the heat consumed by the phase change and the deposition of products in the engine.

3. The combustion process of aluminum powder is a one-step complete reaction, regardless of the reactions of each elements in the product. The combustion process of particles are as follows:

$\mathrm{Al}(\mathrm{s})=\mathrm{Al}(\mathrm{g})$
$4 \mathrm{Al}(\mathrm{g})+3 \mathrm{O}_{2}=2 \mathrm{Al}_{2} \mathrm{O}_{3}(\mathrm{~g})$

(4) Without considering the influence of the gravity and other physical forces, the radiant heat in the reaction is ignored.

\subsection{Physical Model}

In order to save time and resources in the calculation process, Maciel and Marques (2019) conducted a two-dimensional computational fluid dynamics (CFD) simulation was performed on the hydrogenair mixture of a hydrogen fuel single pulse detonation engine. The results show that the two-dimensional model can accurately simulate the engine fuel mixing process. Therefore, the powder fuel scramjet model is a two-dimensional plane model. The structure design is shown in Fig.1. The engine adopts "isolation + cavity combustion chamber + expansion section", in which the cavity adopts the scheme of first expansion and then convergence. The total length of the model is $2580 \mathrm{~mm}$, in which the isolation section is $400 \mathrm{~mm}$, the cavity is $830 \mathrm{~mm}$, and the expansion angle of the expansion section is $6^{\circ}$. The aluminum powder fuel injection port is $100 \mathrm{~mm}$ in front of the exit of the isolation section, and the width is $5 \mathrm{~mm}$. The primary jet inlet is $20 \mathrm{~mm}$ in front of the fuel inlet and has a width of $3 \mathrm{~mm}$.

The ANSYS ICEM is used to construct a complete structured grid for the internal flow field of the scramjet. Due to the complicated flow near the jet ourtlet, it is necessary to refine the area of the jet outlet. Considering the influence of the boundary layer and structural changes in the combustion chamber on the flow field, mesh refinement is carried out at the wall and structural changes. The result is shown in Fig. 2.

\subsection{Governing Equations}

\subsubsection{Gas Phase Governing Equation}

The computational fluid dynamics software ANSYS FLUENT 17.0 is used to numerically simulate the combustion flow process in the combustion chamber of the engine. The gas phase equations are all established in the Eulerian coordinate system. In Cartesian coordinate system $(x, y, Z, t)$, the N-S equation including various components and chemical reactions has the following form (Shreekala and Sridhara 2019):

$\frac{\partial U}{\partial t}+\frac{\partial E}{\partial x}+\frac{\partial F}{\partial y}=\frac{\partial E_{v}}{\partial x}+\frac{\partial F_{v}}{\partial y}+S$

\subsubsection{Particle Phase Governing Equation}

For the discrete phase particles, the discrete phase model is selected to describe the movement and energy exchange process in the flow field. This method is suitable for the case where the particle phase volume of the powder fuel ramjet does not exceed $10 \%$ of the total volume. In the Lagrangian coordinate system, the instantaneous dynamic equation of particles are as follows: 
H. M. Ding et al. / JAFM, Vol. 15, No. 1, pp. 117-127, 2022.

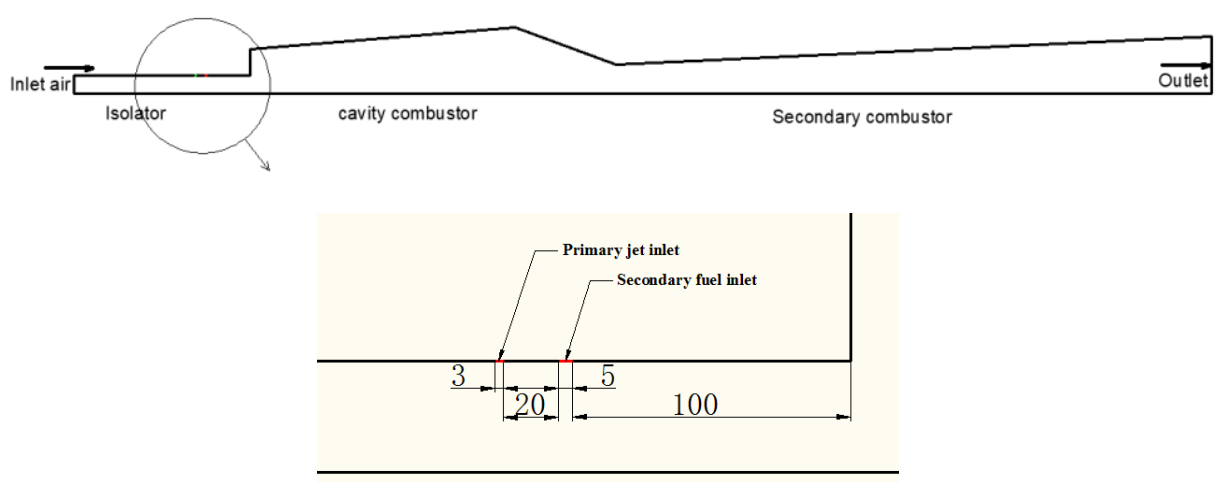

Fig. 1. Powder fuel scramjet model (mm).

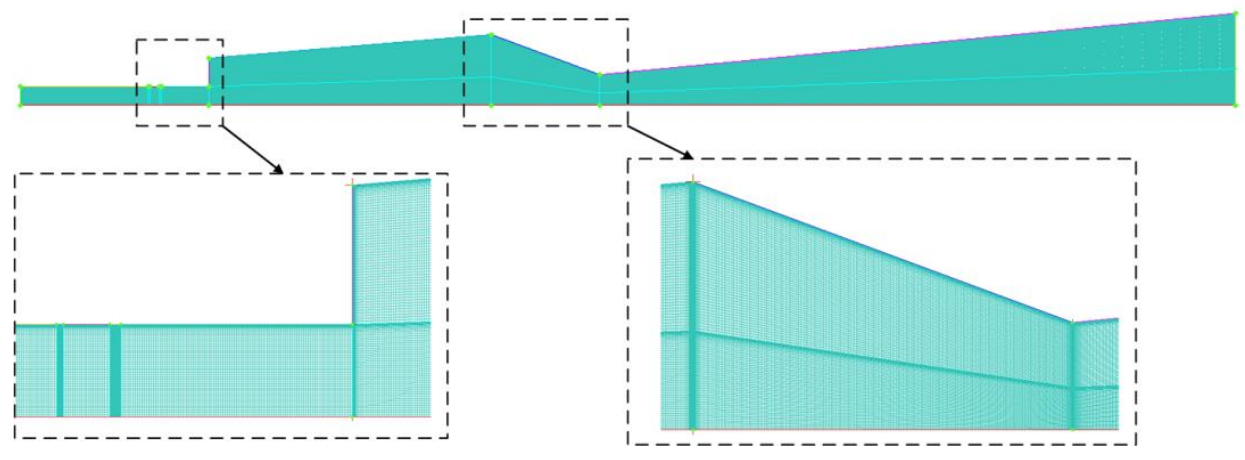

Fig. 2. Grid distribution in the combustion chamber.

$\frac{d X_{s i}}{d t}=v_{s i}$

$\frac{d v_{s i}}{d t}=F_{D}\left(\overrightarrow{v_{g i}}-v_{s i}+v_{g i}^{\prime}\right)$

Where: $\boldsymbol{X}_{\mathrm{si}}$ is the position of particles in the combustion chamber; $\overrightarrow{\boldsymbol{v}_{\mathrm{g}}}$ is the average velocity of the gas phase in direction $\mathrm{I} ; \boldsymbol{v}_{\mathrm{gi}}$ is the pulsating velocity of the gas phase in direction $\mathrm{I}$; $\boldsymbol{v}_{\mathrm{si}}$ is the instantaneous velocity of the particle phase in direction $\mathrm{I} ; F_{\mathrm{D}}$ is the resistance to particles.

\subsubsection{Evaporation Model of Aluminum Particles}

In this study, a constant rate model is used to simulate the process of the aluminium vapor precipitation from particles. The volatiles are separated at a fixed rate, and the particle diameter does not change during the process. The mass transfer equation of particles is as follows:

$-\frac{1}{f_{v, 0}\left(1-f_{w, 0}\right) m_{p, 0}} \frac{d m_{p}}{d t}=A_{0}$

Where: $m_{p}$ is the mass of particles; $m_{p, 0}$ is the initial mass of particles; $f_{v, 0}$ is the mass fraction of gaseous aluminum in particles at the initial time; $f_{w, 0}$ is the mass fraction of vaporizable / boiling substances in particles when choosing wet combustion particles, if not, $f_{w, 0}=0 ; A_{0}$ is the precipitation rate constant (unit: $\left.\mathrm{s}^{-1}\right)$.

In the evaporation process of the aluminium vapor, the heat transfer equation of its phase with surrounding fluid is as follows:

$m_{p} C_{p} \frac{d T}{d t}=h A\left(T_{\infty}-T_{p}\right)+\frac{d m_{p}}{d t} h_{f g}+\varphi$

In the formula, $C_{p}$ is the specific heat capacity of particles; $T_{p}$ is the particle temperature; $T_{\infty}$ is the external environment temperature; $h_{f g}$ is the volatile heat absorption rate; $\Phi$ is the dissipative phase in the heat transfer process.

\subsection{Combustion Model}

It is assumed that the fuel will completely evaporate after entering the engine and participate in the reaction, this study only considers gas phase combustion, so a finite rate model is selected to describe the aluminium reaction process. In the finite rate model, the Arrhenius formula is used to calculate the chemical source term, while the effect of turbulence fluctuation is ignored. The reaction rate is controlled by the Arrhenius equation

$k=A \exp (-E R / T)$ 
where, $K$ is the reaction rate constant, $A$ is the preexponential factor; $E$ is the reaction activation energy; $T$ is the absolute temperature; $R$ is the gas molar constant.

\subsection{Boundary Conditions}

(1) The boundary condition of air inlet: the mass flow rate inlet is adopted. Given that the mass flow rate of the incoming air at the inlet is $26 \mathrm{~kg} / \mathrm{s}$, the static pressure is $159296 \mathrm{pa}$, the total temperature is $1308 \mathrm{k}$ and the inlet Mach number is 1.7;

(2) The boundary condition of powder fuel inlet: The mass flow rate inlet is adopted. Because aluminium powder particles need to be transported by the fluidizing gas. The mass flow rate is $0.5 \mathrm{~kg} / \mathrm{s}$, the static pressure is $120000 \mathrm{pa}$, total temperature was $300 \mathrm{~K}$, mass flow rate of the aluminum powder fuel is $3.4 \mathrm{~kg} / \mathrm{s}$. The particle diameter is $20 \mu \mathrm{m}$;

(3) The boundary conditions of primary jet: The jet inlet boundary conditions are shown in Table 1 . The total gas temperature is $300 \mathrm{~K}$.

Table 1 Jet mass flow rate under the different conditions

\begin{tabular}{|c|c|}
\hline Working condition & $\begin{array}{c}\text { Jet mass flow rate } \\
(\mathrm{kg} / \mathrm{s})\end{array}$ \\
\hline Case 1 & 0 \\
\hline Case 2 & 0.2 \\
\hline Case 3 & 0.35 \\
\hline Case 4 & 0.5 \\
\hline Case 5 & 0.65 \\
\hline Case6 & 0.8 \\
\hline
\end{tabular}

(4) Wall boundary conditions: the velocity on the wall of isolation section, cavity and expansion section are no-slip condition, the temperature is adiabatic wall, and the gradient of pressure and mass fraction of each component are zero.

\section{Validation of numerical methods}

In order to verify the reliability of the calculation method, this section uses the Santigao and Dutton (1997) experimental model and basic grid to verify the experiments of Santigao and Dutton (1997), Everett et al. (2015) and Vanlerberghe et al. (2011). The calculation results are compared with the experimental results. The experiment was carried out in a supersonic wind tunnel with a Mach number of 1.6 , the total pressure of the incoming flow was $241 \mathrm{kPa}$, and the total temperature was $296 \mathrm{~K}$. The total pressure of the jet was $476 \mathrm{kPa}$, the total temperature was $295 \mathrm{~K}$, and the experimental jet flow pressure ratio was 1.7. Both jet and free-stream were air, of which the specific heat $\gamma$ was 1.4. The origin of the coordinate was located at the center of the jet nozzle and located in the center of the bottom wall with the diameter $\mathrm{D}=4 \mathrm{~mm}$. The calculation length of $\mathrm{x}, \mathrm{y}$ and $\mathrm{z}$ directions are: $-7.5<\mathrm{x} / \mathrm{D}<10,0<\mathrm{y} /$ $\mathrm{D}<8,-5<\mathrm{z} / \mathrm{D}<5$. Figure 3 shows the results of experimental Schlieren and predicted contours of density gradient of mean flow field for $J=1.7$. The location of reflected shock was well reproduced by prediction. The velocity distribution in the experiment was extracted and compared with the numerical calculation results used in this study. The comparison result is shown in Fig. 4. It can be seen from the figure that the numerical calculation results match the experimental results well, thus confirming the reliability of the calculation results. Obvious differences were observed in the downstream area of the jet, which may be due to the uncertainty of the experimental data.

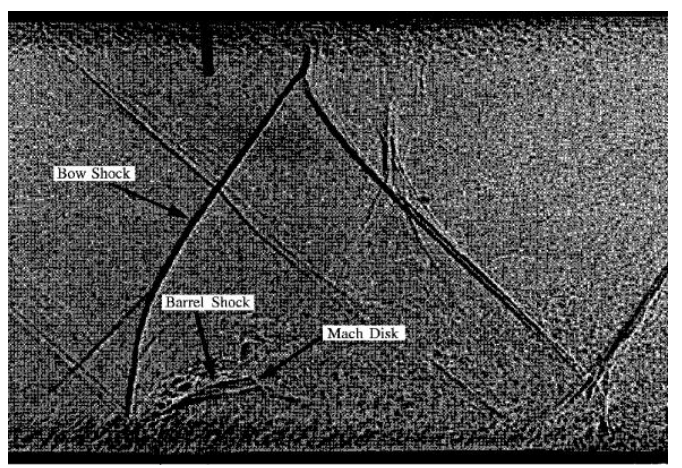

(a) Experimental Schlieren results

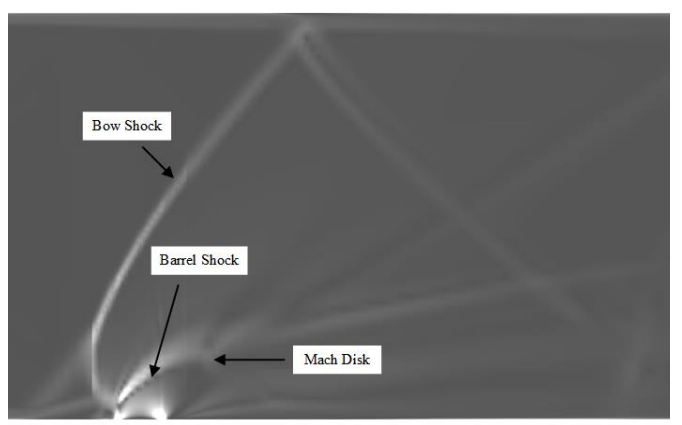

(b) Simulation Schlieren results

Fig. 3. Comparison of experimental Schlieren results and simulation Schlieren results.

\section{RESULTS AND ANALYSIS}

\subsection{Grid distribution and independence analysis}

The grid layout in the calculation area has a significant impact on the calculation results. Therefore, it is necessary to evaluate the independence of the distribution network. Three different grid distributions were evaluated: coarse grid is 0.1 million elements, moderate grid is 0.3 million elements, and refined grid is 0.6 million elements, Figure 5 shows the variation of Mach number along the axis under three different grid 


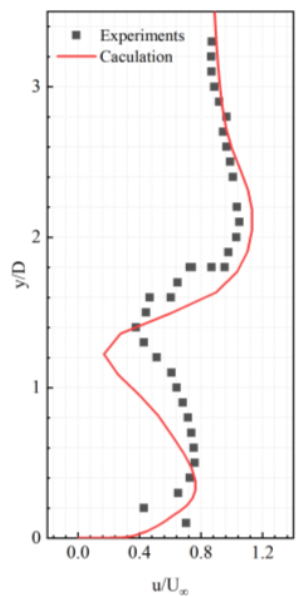

(a) $\mathbf{x} / \mathbf{D = 2}$

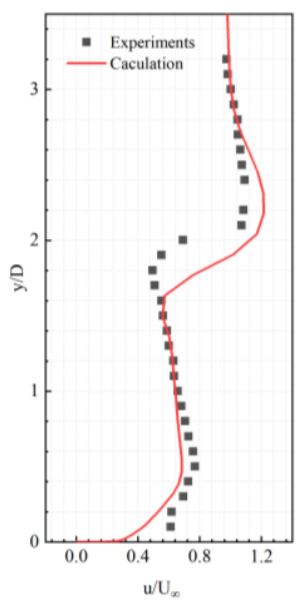

(b) $x / D=3$

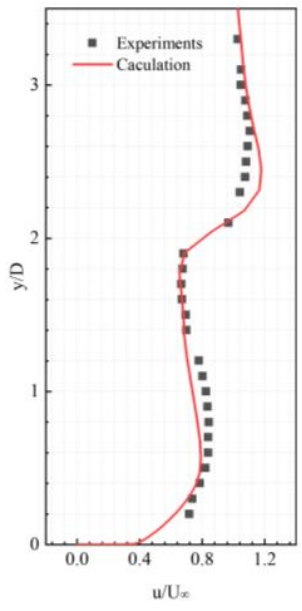

(c) $\mathrm{x} / \mathrm{D}=\mathbf{4}$

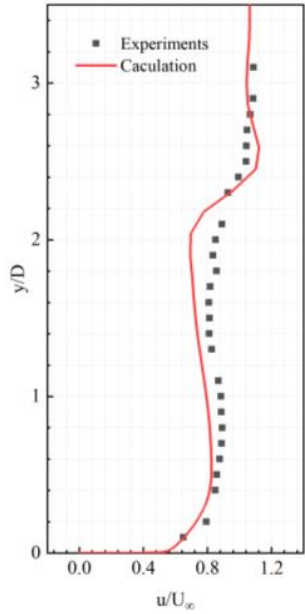

(d) $x / D=5$

Fig. 4. Comparisons of fluctuating stream wise velocity statistics profiles between simulation and experiments of Santiage $\&$ Dutton in the central plane at four locations.

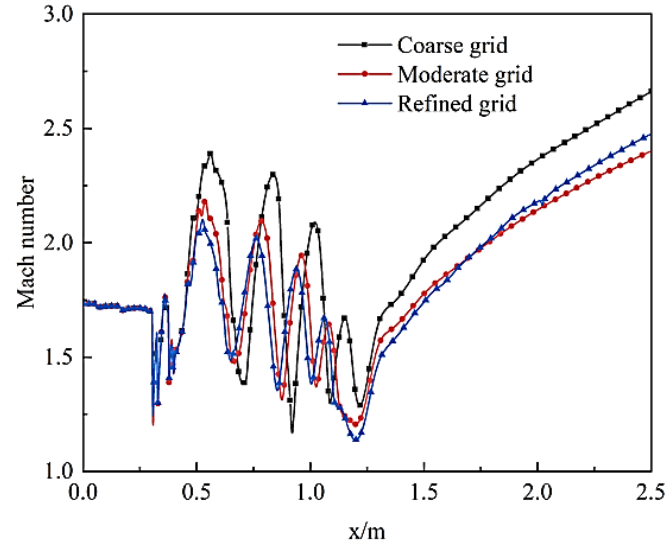

Fig. 5. Mach number along the axis under three different grid distribution.

distributions. It can be seen that when the grid reaches a certain number, the numerical results tend to be stable. Finally, in order to save computing resources, 400,000 grids are used for numerical calculations.

\subsection{The Influence of Primary Jet on the Flow Field in Cold Flow}

Figure 6 shows Mach number, pressure and temperature distribution under the single-hole jet and double-hole jet conditions in the two-dimensional model. The single-hole jet flow field structure in the isolation section is shown in Fig. 6 (a), (c) and (e). Due to the interactions between supersonic crossflow and the transverse injected powder fuel jet, complex phenomena can be observed. The supersonic cross-flow is blocked by the powder fuel injected from the upper wall, forming an oblique shock wave upstream of the fuel jet. The oblique shock wave is compressed to after the shock wave to form a high temperature, which is conducive to the ignition of the downstream fuel; due to the interaction between the oblique shock wave and the upstream boundary layer, a back pressure gradient is formed, which causes the boundary layer to separate, and a low-velocity zone is formed at downstream of the fuel injection inlet.

Figure 6 (b), (d), (f) show the flow field structure in the isolation section when the primary jet flow is $0.5 \mathrm{~kg} / \mathrm{s}$. It can be seen that the structure of the flow field near the primary jet under the double-hole jet condition is similar to the that of single-hole jet. However, due to the low mass flow rate of the primary jet and the insufficient penetration momentum in the supersonic mainstream, the penetration depth of the jet is shallow, the blocking effect on the mainstream is not obvious. The intensity of the oblique shock wave is low, and the area of the low-velocity area downstream of the primary jet inlet is small. The area of a low-velocity formed downstream of the powder fuel injection inlet is larger than that of the single-hole jet. The blocking effect of the primary injection reduces the momentum of the main flow upstream of the powder fuel injection, so that the powder fuel has a deeper penetration depth, which is beneficial to the mixing of the powder fuel and air in the combustion chamber. To analyze the influence of the primary jet flow on the flow field structure. Figure 6 shows the contour of Mach number distribution in the isolation section under different primary jet flow rates. It can be seen from the figure that the main flow is blocked by the primary jet on the wall, forming an oblique shock wave upstream of the jet inlet. The upward and downward oblique shock waves intersect at the center of the isolation section to form an X-shaped structure, and a Mach disk is formed at the center of the X-shaped structure. It can be seen from Fig. 7 (b) that a first oblique shock wave is formed at upstream of the primary jet inlet, and the second oblique shock wave is formed at the powder fuel 


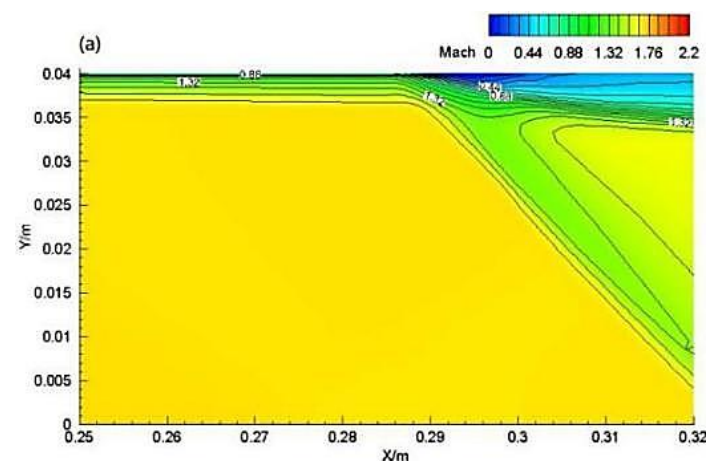

(a) Single-hole jet

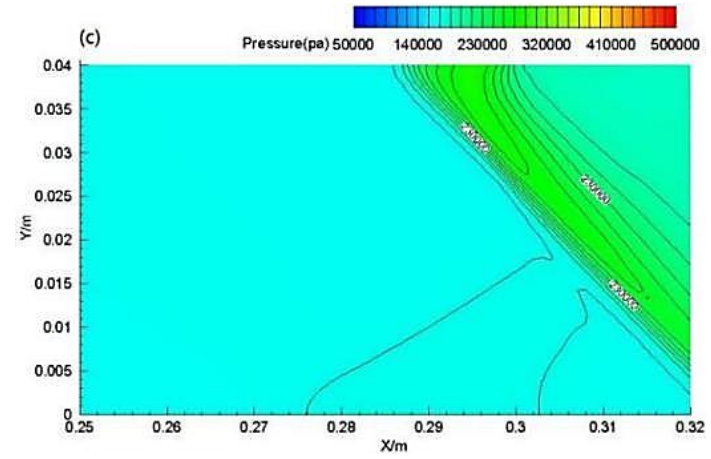

(c) Single-hole jet

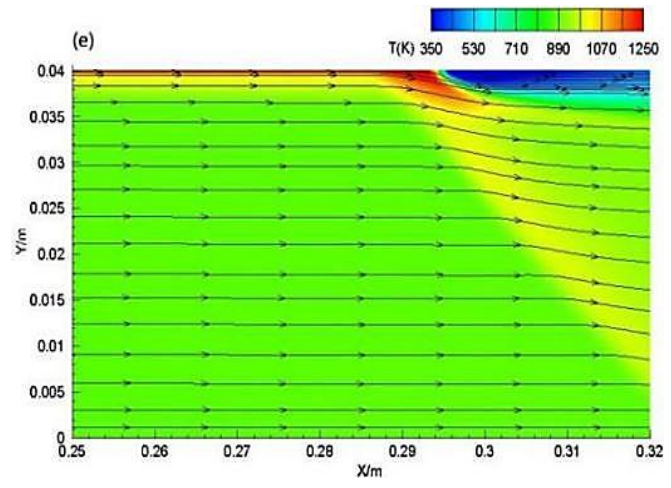

(e) Single-hole jet

Fig. 6. Cloud chart of Mach number, pressure, velocity streamline and temperature under different working conditions.

injection inlet. However, the primary jet has a lower penetration depth and a thinner shear layer. The powder fuel penetrates the shear layer formed by the primary jet and enters the supersonic mainstream. The supersonic mainstream is blocked again to form a second oblique shock wave, which is weaker than the first oblique shock wave. With the increase of the primary jet flow rate, the thickness of the shear layer formed by the primary jet becomes larger, while the second oblique shock intensity caused by the secondary powder fuel gradually decreases until it disappears.

Under the influence of the primary jet, the area of the low-velocity region at downstream of the secondary fuel inlet is larger than that without the primary jet. And with the increase of the primary jet flow, the area

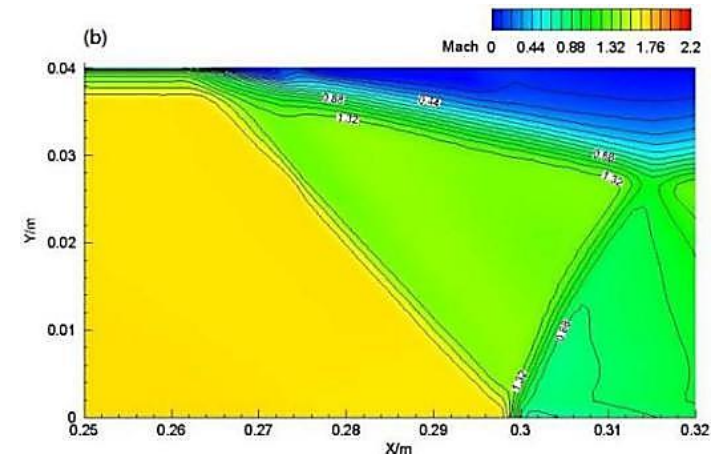

(b) Primary jet mass flow rate $0.5 \mathrm{~kg} / \mathrm{s}$

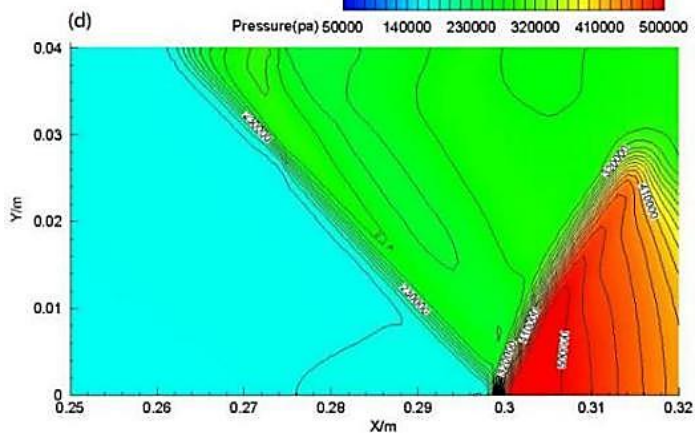

(d) Primary jet mass flow rate $0.5 \mathrm{~kg} / \mathrm{s}$

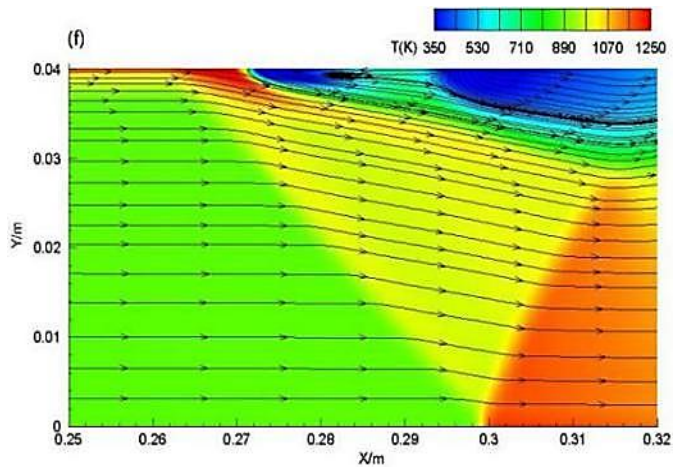

(f) Primary jet mass flow rate $0.5 \mathrm{~kg} / \mathrm{s}$

increases first and then decreases. The reason is that as the flow rate of the primary jet increases, the blocking effect of the primary jet on the supersonic flow becomes more obvious. The position of the Xtype shock wave moves forward, and the intensity of the middle positive shock wave increases. The formation of the high-pressure region reduces the area of the low-speed region downstream of the secondary powder fuel inlet.

\subsection{Analysis of Mixing Characteristics of Primary Jet Powder Fuel}

The scramjet fueled by powder particles has a large particles diameter and a short residence time in the combustion chamber. The agglomeration of powder fuel in the combustion chamber is difficult to 


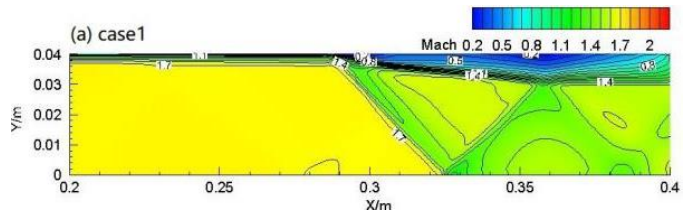

(a) case 1

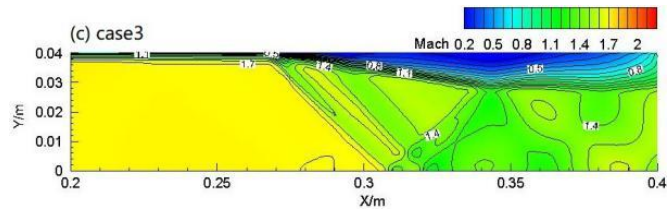

(c) case 3

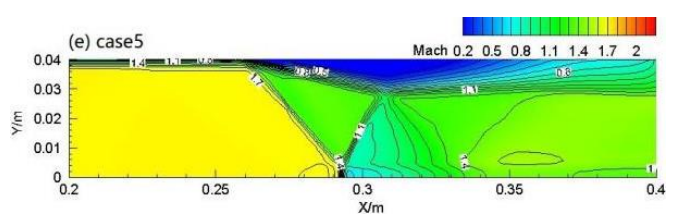

(e) case5

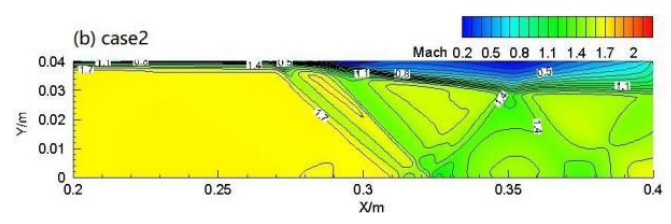

(b) case2

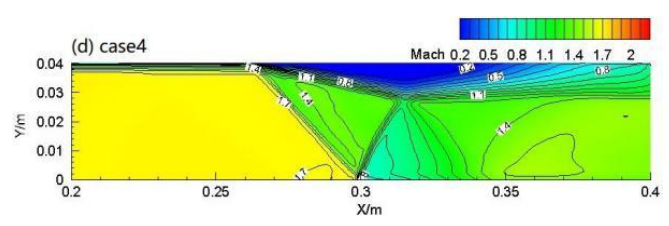

(d) case4

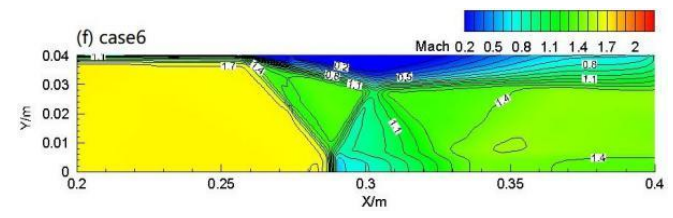

(f) case6

Fig. 7. Mach number and trace distribution under different working conditions.

effectively mix. The combustion process of aluminum particles is mainly caused by the reaction between the gaseous aluminum of the aluminum near the particle surface and the oxidizing gas in the mainstream air. The combustion process is generally controlled by evaporation / diffusion, so the mixing degree of the gas and aluminum particles is very important to the combustion process of particles. According to Hu et al. (2019), the definition of gassolid mixing degree is shown in Eq. (7). The gassolid mixing degree varies from 0 to 1 . The closer to 1 , the higher the mixing degree is. The formula for the degree of mixing is as follows:

$\beta_{p i}=1-\frac{1}{1+\log _{10}\left[1+\frac{\rho v Y_{o 2} n_{p} v_{P} m_{p} \eta_{i}}{\left(\rho v Y_{o 2}-n_{p} v^{m} m_{p} \eta_{i}\right)^{2}}\right]}$

Where: $\beta_{p i}$ is the mixing degree between the particles and the oxygen; $\rho$ is the gas density; is the gas velocity; $v$ is the particle velocity; $v_{p}$ is the particle density; $n_{p}$ is the mass of a single particle; $m_{p}$ is the mass flow ratio of oxygen and $\eta_{i}$ is the particles entering the system.

To simplify the formula for the degree of mixing, the particle velocity and gas velocity are set as axial velocity, which can be simplified in the formula for the degree of mixing.

Figure 8 shows the change of the mixing degree of the aluminum particles with the oxygen in the mainstream under single-hole and double-hole jet. It can be seen from the figure that due to the inertia force of aluminum particles, effective mixing cannot be carried out in the isolation section. In the cavity, the aluminum particles are affected by the velocity of flow field and the internal structure of the cavity, and the degree of mixing increases. With the introduction of primary jet, the area of low-velocity area downstream of powder fuel jet increases, and the flow field structure of the combustion chamber changes, which significantly increases the mixing degree of the aluminum particle and the oxygen.

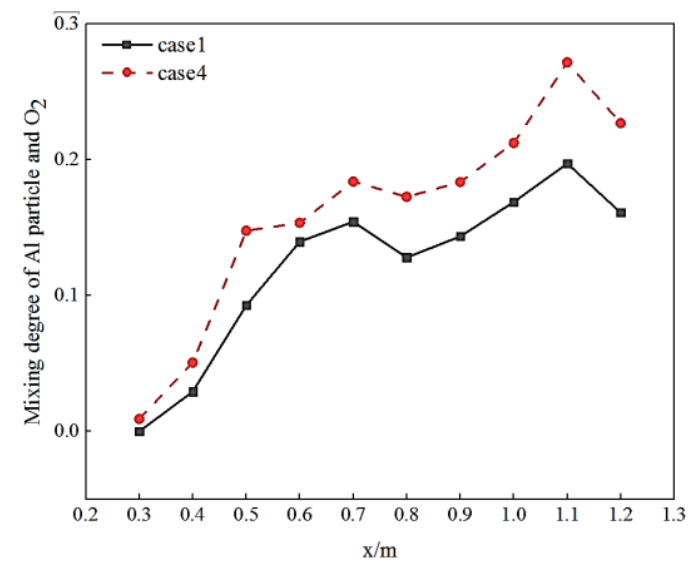

Fig. 8. Mixing degree of the aluminum particles and the oxygen in single-hole and double-hole jet conditions.

Figure 9 shows the trajectory of aluminum particles in the cavity of the single-hole jet and double-hole jet scramjet. Compared with the single-hole jet working condition, it can be seen from the above situation that 
H. M. Ding et al. / JAFM, Vol. 15, No. 1, pp. 117-127, 2022.

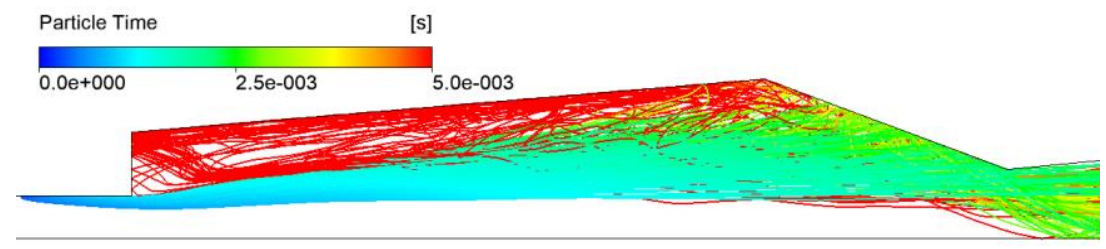

(a) Single-hole jet (case 1)

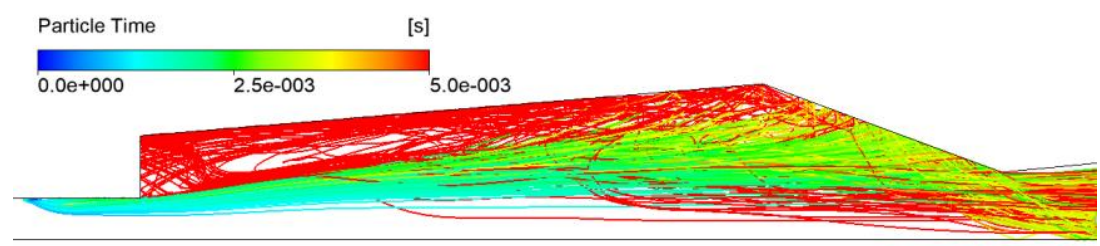

(b) Primary jet mass flow rate $0.5 \mathrm{~kg} / \mathrm{s}$ (case 4)

Fig. 9. Trajectory of aluminum particles in single-hole and double-hole jet conditions.

the action of the main jet changes the flow field in the combustion chamber prolongs the residence time of the powder fuel in the cavity, and expands the distribution range of fuel particles.

\subsection{Analysis of the Effect of Primary Jet on Engine Operation}

When the fuel burns in the combustion chamber, the pressure in the combustion chamber will increase, and the pressure in the combustion chamber will be higher than that in the isolation section. The pressure propagates upstream from the isolation section (the isolation section is called back pressure), and a series of shock waves are formed in the isolation section. If the back pressure of the isolation section propagates upstream to the engine intake, the intake will not be able to start and surge will occur, which will adversely affect the engine performance.

To study the influence of primary jet on the flow field of the isolation section under different working conditions, Fig. 8 shows the pressure distribution and velocity streamline diagram of the isolation section under different working conditions. From the velocity streamline in Fig. 10 (a), it can be seen that in the case of a single-hole jet, a part of the powder fuel and fluidizing gas flow to the upstream of the isolation section for a short distance under the action of the back pressure, and then flow to the isolation section with the supersonic flow. Downstream of the section, so a small recirculation zone is formed in front of the injection port. The supersonic inflow is affected by the part of powder fuel, fluidizing gas and back pressure in the recirculation zone, forming a shock wave. By comparing the different primary jets in Fig.9, it can be seen that as the flow of the primary jet increase, the position of shock wave moves forward in turn. When the primary jet flow rate is $0.8 \mathrm{~kg} / \mathrm{s}$, the shock wave position is the most forward, followed by the primary jet flow rate of $0.2 \mathrm{~kg} / \mathrm{s}$.
Combined with the combustion efficiency curve given in Fig. 10 and comparing operating condition 5 and 6 , it can be seen that the primary jet flow is the main factor affecting the shock wave position when the powder fuel combustion efficiency is basically the same. Compared with the case 2 and case 6 , the impact of the injection flow rate on the shock position is greater than the combustion efficiency of the powder fuel.

Aluminum particles are used as fuel in the combustion chamber of powder fuel scramjet. It is a great significance to study the combustion efficiency of aluminum particles. In this study, the reaction of aluminum is a one-step at a time, and the combustion product is $\mathrm{Al}_{2} \mathrm{O}_{3}$. The combustion efficiency of particles is calculated from the $\mathrm{Al}_{2} \mathrm{O}_{3}$ content in the outlet section of combustion chamber, and the calculation expression is:

$\eta_{c}^{*}=\frac{\int \rho u Y_{i, g} d A}{M_{P, 0}}$

Where: $\eta_{c}^{*}$ is the combustion efficiency of particles; $\rho$ is the density; $u$ is the velocity; $Y_{i, g}$ is the mass fraction of $\mathrm{Al}_{2} \mathrm{O}_{3} ; M_{p, 0}$ is the total reaction mass of inlet $\mathrm{Al}$ particles.

Figure 11 shows the combustion efficiency curve of powder fuel under different conditions. It can be seen from the curve that the introduction of the primary jet can significantly improve the combustion efficiency of powder fuel. As the flow rate of the primary jet increases, the combustion efficiency of powder fuel increases first and then decreases. Among them, the combustion efficiency of the single-hole jet is only 0.4934 . The combustion efficiency is 0.6677 when the primary jet flow rate is $0.2 \mathrm{~kg} / \mathrm{s}$, which is $17.43 \%$ higher than the single-hole jet. The reason for improving the combustion efficiency of the 


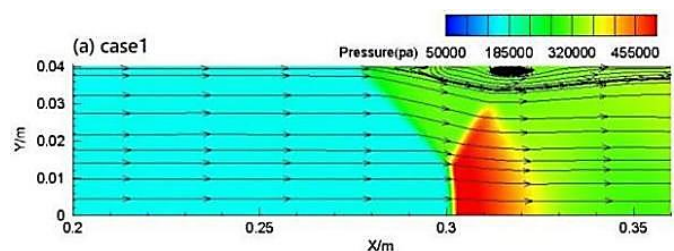

(a) Case1

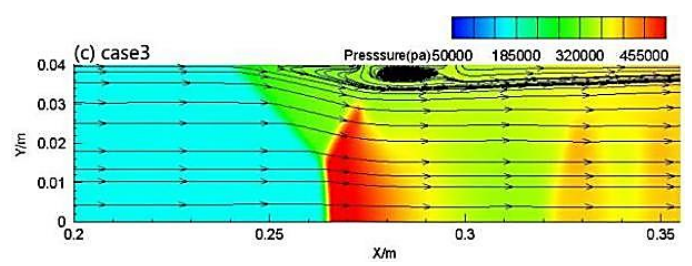

(c) Case 3

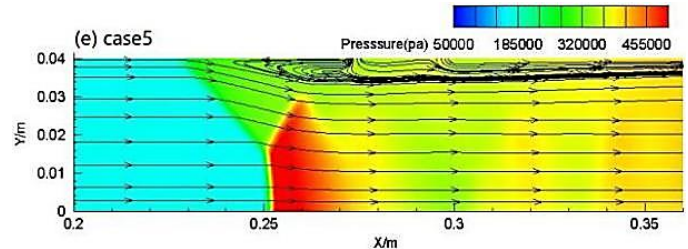

(e) Case5

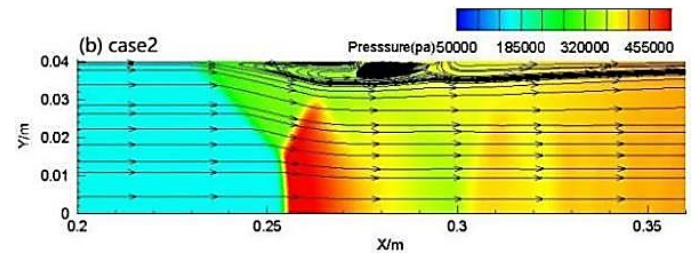

(b) Case2

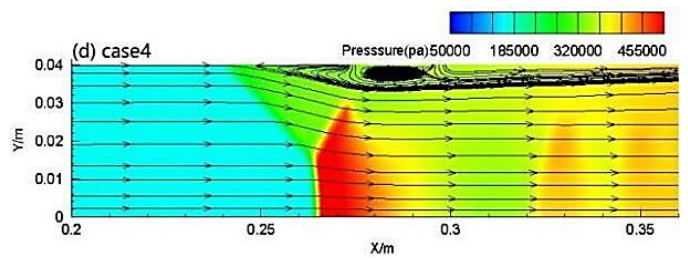

(d) Case4

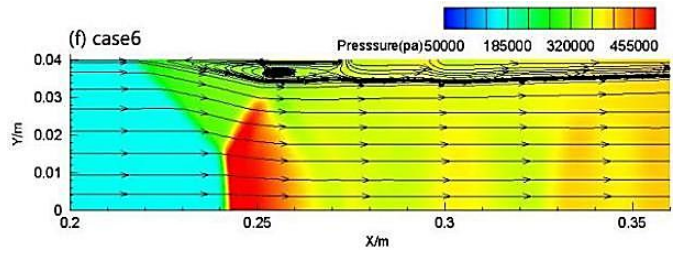

(f) Case6

Fig.10 Pressure distribution contour and velocity streamline in the isolation section under different working conditions.

powder fuel is that the primary jet improves the mixing degree of powdered fuel in the combustion chamber, so the combustion reaction of powdered fuel in the combustion chamber is more complete.

To analyze the performance of the powder fuel scramjet more accurately, the thrust of the engine is calculated as follows:

$F_{x}=\int\left(P+\rho u^{2}\right) d A$

$\Delta F_{x}=F_{\text {out }}-F_{\text {in }}$

Figure 11 shows the thrust curve of powder fuel scramjet under the different conditions. It can be seen from the curve that the introduction of the primary jet can significantly increase the engine thrust. With the increase of the primary jet flow, the engine thrust increases and then decreases. The main reason is that the primary jet can effectively improve the mixing degree of the powder fuel, so that the powder fuel is burned more fully in the combustion chamber, and the pressure in the combustion chamber increases, resulting in a larger axial thrust. When the flow rate of the primary jet is $0.35 \mathrm{~kg} / \mathrm{s}$, the maximum thrust is about $15 \%$ higher than that the single-hole jet.

\section{CONCLUSION}

In this study, a model of a scramjet fueled by aluminum powder is established, and the effect of primary jet on the flow and combustion characteristics of the scramjet is studied:
(1) As the flow rate of the primary jet increase, the intensity of the oblique shock wave generated upstream of the primary jet increases, the penetration depth of the secondary jet increases, and the area of the low-velocity region downstream of the fuel jet increases first and then decreases.

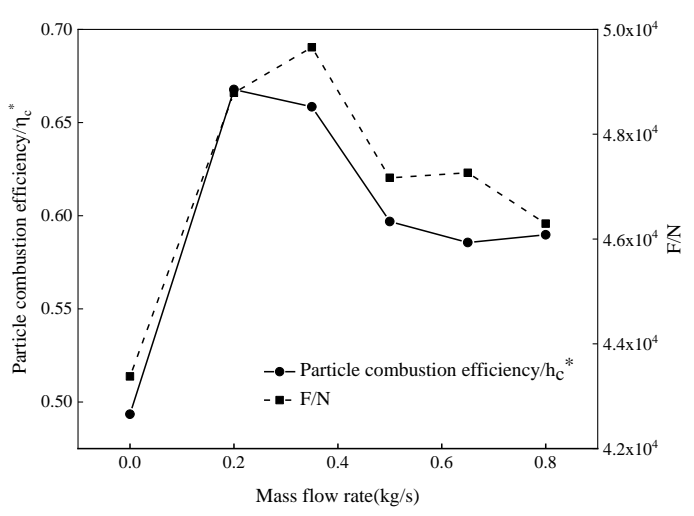

Fig. 11. Particle combustion efficiency and Scramjet thrust under different working conditions.

(2) The introduction of primary jet can effectively improve the mixing degree of powder fuel particles in the combustion chamber, prolong the residence time of powder fuel particles, and expand the particle distribution range.

(3) The introduction of primary jet has a great influence on the performance of the engine. With the 
increase of primary jet flow, the combustion efficiency of powder fuel and the engine thrust increase first and then decrease. The combustion efficiency is the highest when the primary jet flow is $0.2 \mathrm{~kg} / \mathrm{s}$, which is $17.43 \%$ higher than the single-hole jet. When the primary jet flow is $0.35 \mathrm{~kg} / \mathrm{s}$, the engine thrust is the largest, which is about $15 \%$ higher than the single-hole jet.

\section{ACKNOWLEDGEMENTS}

This thesis is partially supported by National Natural Science Foundation of China (No.11802134); China Postdoctoral Science Foundation (No.2018M642255) and Jiangsu Provincial Natural Science Foundation, China.(No.BK20180453).

\section{REFERENCES}

Anugrah, G., P. Raja, M. Deepu and R. Sadanandan (2019). Experimental and Numerical Studies of Secondary Injection in Nozzle Divergence for Thrust Augmentation. Journal of Applied Fluid Mechanics 12(5), 1219-1728.

Aryadutt O. and R. Sadanandan (2019). Fuel injection location studies on pylon-cavity aided jet in supersonic crossflow. Aerospace Science and Technology 92, 869-880.

Barzegar Gerdroodbar, M., M. Rahimi Takami and H. R. Heidari (2016). Comparison of the single/multi transverse jets under the influence of shock wave in supersonic crossflow. Acta Astronautica 123, 283-291.

Barzegar Gerdroodbary, M., R. Moradi and Iskander Tlili (2019). The influence of upstream wavy surface on the mixing zone of the transverse hydrogen jet at supersonic free stream. Aerospace Science and Technology 94, 105407.

Chapuis, M., E. Fedina, C. Fureby and K. Hannemann (2013). A computational study of the HyShot II combustor performance. Proceedings of the Combustion Institute 34, 2101-2109.

Everett, D. E., M. A. Woodmansee, J. C. Dutton and M. J. Morris (2015). Wall pressure measurements for a sonic jet injected transversely into a supersonic crossflow. The Journal of Propulsion and Power 14, 861-868.

Fuller, R. P., P. K. Wu, A. S. Nejad and J. A. Schetz (1998). Comparison of physical and aerodynamic ramps as fuel injectors in supersonic flow. Journal of Propulsion and Power 14 (2), 135-145.

Gerdroodbary, M. B., M. R. Takami, H. Heidari, K. Fallah and D. Ganji (2016). Comparison of the single/multi transverse jets under the influence of shock wave in supersonic crossflow. Acta Astronaut. 123, 283-291.

Goroshin, S., A. Higgins and M. Kamel (2001). Powdered metals as fuel for hypersonic ramjets. 37th Joint Propulsion Conference and Exhibit, Salt Lake City, Utah, AIAA, 3919.

Gruber, M. R., J. M. Donbar and C. D. Carter (2004). Mixing and combustion studies using cavitybased flameholders in a supersonic flow. Journal of Propulsion and Power 20 (5), 769778.

Hu J., C. Hu, Y. Li, C. Li, X. Hu and X. Zhu (2019). Numerical simulation of spoiler ring's effect on combustion and flow of powdered rocket motor. Journal of Aerospace Powder 34(7), 15581567.

Hu, C., C. Li, H. Sun and G. Wu (2017). A summary of powder-fuelde ramjet. Journal of Solid Rocket Technology 40(3), 269-276.

Huang, W., Z. G. Wang and S. Luo (2011). Overview of fuel injection techniques for scramjet engines. Proceedings of the American Society of Mechanical Engineers Turbo Expo, 17-24.

Li, Y., M. B.Gerdroodbary, R. Moradi and . Babazadeh (2020). The influence of the sinusoidal shock generator on the mixing rate of multi hydrogen jets at supersonic flow. Aerospace Science and Technology 96, 105579.

Li, Z., D. M. Tran and M. B. Gerdroodbary (2020). The effect of sinusoidal wall on hydrogen jet mixing rate considering supersonic flow. Energy 193, 116801.

Liang, C. H., M. Sun, Y. Liu and Y. X. Yang (2018). Shock wava structuresin the wake of sonic transverse jet into a supersonic crossflow. Acta Astronautica 148, 12-21

Liang, C. H., M. Sun, Y. Liu and X. G. Li (2020). Numerical study of flow structures and mixing characteristics of a sonic jet in supersonic crossflow. Acta Astronautica 166, 78-88

Maciel, E. C., C. S. and T. Marques (2019). 2-D Simulation with $\mathrm{OH}^{*}$ Kinetics of a SingleCycle Pulse Detonation Engine. Journal of Applied Fluid Mechanics 12(4), 1249-1263.

Mahesh, K. (2013). The interaction of jets with crossflow. Annual Review of Fluid Mechanics, 45, 379-407.

Pudsey A. S. and R. R. Boyce (2010). Numerical investigation of transverse jets through multiport injector arrays in a supersonic crossflow. The Journal of Propulsion and Power, 26 (6), 1225-1236.

Santigao J. G. and J. C. Dutton (1997). Velocity measurements of a jet injeted into a supersonic 
H. M. Ding et al. / JAFM, Vol. 15, No. 1, pp. 117-127, 2022.

crossflow. The Journal of Propulsion and Power 13(2), 264-273

Shen, H., Z. Xia and J. Hu (2007). Numerical simulation on two-phase flow in the powder fuel ramjet combustor. Journal of Solid Rocket Technology 30(6), 474-477.

Shen, H., Z. Xia and J. Hu (2008). Preliminary experimental investigation on metal-powder fuel ramjet. Journal of Solid Rocket Technology 31(3), 225-227.

Shen, H., Z. Xia and J. Hu (2009). Experimental investigation on self-sustaining combustion of powdered metal fuel ramjet. Journal of Solid Rocket Technology 32(2),145-149.

Shreekala, N. and S. N. Sridhara (2019). Numerical Investigation of influence of flow rates on combustion characteristics using multiphase flamelet combustion. Journal of Applied Fluid Mechanics 12 (4), 1013-1021.

Smart M. K. and N. E. Hass (2006). Paull Flight data analysis of the HyShot 2 scramjet flight experiment. AIAA 44 (10), 2366-2375.

Sun, M. and Z. Hu (2018). Formation of surface trailing counter-rotating vortex pair downstream of a sonic jet in a supersonic cross-flow. Journal of Fluid Mechanics 850, 551-583

Taherinezhad, R. and G. Zarepour (2019). Numerical and Experimental Investigation of Secondary Injection with a Novel Pyrogenic Pulser.
Journal of Applied Fluid Mechanics 12(6), 2039-2055.

Vanlerberghe, W. M., J. G. Santiago, J. C. Dutton and R. P. Lucht (2011). Mixing of a sonic transverse jet injected into a supersonic flow. AIAA 38, 470-479.

Vatslya, S., E. Vinayak and D. Chakraborty (2020). Determination of optimal apacing between transverse jets in a SCRAMJET engine. Aerospace Science and Technology 96, 105520.

Wei, H., Y. Li, L. Yan and R. Moradi (2018). Mixing enhancement mechanism induced by the cascaded fuel injectors in supersonic flows: A numerical study. Acta Astronautica 152, 18-26.

Wen, X., J. Liu, Z. Liu, Z. Xia and L. Jin (2019). Assessment of numerical method by experimental date for integrated hypersonic vehicles. Journal of Applied Fluid Mechanics 12(3), 657-665.

You, Y. C., L. Heibrich and H. Klaus (2013). Injection and mixing in a scramjet combustor: DES and RANS studies. Proceedings of the Combustion Institute, 34, 2083-2092.

Zhao, M., T. Ye, C. Cao and T. Zhou (2016). Study of sonic injection from circular injector into a supersonic cross-flow using large eddy simulation. International Journal of Hydrogen Energy 41(39), 17657-17669. 